\title{
Abortamento na adolescência: da vida à experiência do colo vazio - um estudo qualitativo
}

\author{
Abortion in the adolescence: \\ from life to the experience of the empty lap - a qualitative study
}

Leila M aria Vieira $^{1}$

Tamara Beres Lederer Goldberg ${ }^{2}$

Sandra de Oliveira Saes ${ }^{1}$

Adriana A parecida Bini Dória ${ }^{1}$

${ }^{1}$ Universidade do Sagrado

Coração. Rua Irmã Arminda 10-50, Jardim Brasil.

17011-160 Bauru SP. leila.vieira@usc.br

${ }^{2}$ Faculdade de M edicina de

Botucatu, Universidade

Estadual deSão Paulo.
Abstract The present study aimed to investigate the process of abortion in the adolescence, according to adolescence perspective at Santa Izabel Maternity Hospital, in the city of Bauru - São Paulo, Brazil. The qualitative methodology tried to understand the adolescent's experience on the abortion process, building a theoretical sample that represents it. Symbolic interacionism was used as referential theory and grounded theory as methodological reference. Ten adolescents were interviewed and the analyses of the reports noticed the discovered of pregnancy, emergent feelings, the difficult moment of hospitalization, the hope for a return to quotidian followed by relatives help and the need of changes because of this experience. From the reports three phenomena were observed: find yourself pregnant; living the abortion and remaking of the life plan. From the analyses of the process it was developed the central category: "Abortion on adolescence: from life to the experience of empty lap". The occurrence of abortion in the adolescence causes different feelings and may reach bio psychosocial circles. Key words Adolescent, Abortion, Qualitative research
Resumo 0 presente estudo teve como objetivo investigar o processo de abortamento na adolescência, segundo a perspectiva da adolescente. Foi desenvolvido no $\mathrm{H}$ ospital $\mathrm{M}$ aternidadeSanta Izabel, da cidade de Bauru (São Paulo, Brasil), e a metodologia qualitativa buscou compreender a experiência da adolescente no processo de abortamento, construindo um modelo teórico representativo. Utilizou-se como referencial teórico o interacionismo simbólico e como metodológico a grounded theory. Foram entrevistadas dez adolescentes, ea análise dos relatos constatou a descoberta da gravidez, os sentimentos emergentes, 0 difícil momento da internação, a esperança do retorno ao cotidiano acompanhado pelo apoio dos familiares ea necessidade de mudanças decorrentes de tal experiência. Dos depoimentos emergiram três fenômenos: descobrindo-se grávida, vivenciando 0 abortamento e reelaborando o plano de vida. A partir da análise do processo, desenvolveu-se a categoria central: "Abortamento na adolescência: da vida à experiência do colo vazio". Conclusão: a ocorrência do abortamento na adolescência causa diferentes sentimentos, podendo atingir as esferas biopsicossociais.

Palavras-chave Adolescente, Abortamento, Pesquisa qualitativa 
Introdução

Segundo a Organização Mundial da Saúde'1, os limites da adolescência se estendem dos dez aos 19 anos. Caracteriza-se por um período crítico do desenvolvimento e de transformações biopsicossociais, com repercussões em vários setores do desenvolvimento humano, dentre eles a saúde sexual e reprodutiva ${ }^{2,3}$. A adolescência é um período marcado por transformaç̧ões corporais intensas e radicais, que caracterizam a puberdade, e por modificações psicológicas e sociais, as quais se refletirão na construção da personalidade do indivíduo 4 .

Decorrente de tal situação, a adolescente se expõe aos mesmos riscos de gravidez de uma mulher adulta, podendo ela ser ou não planejada e, muitas das vezes, indesejada. Vários estudos referem quea primeira experiência sexual vem acontecendo cada vez mais precocemente, ocorrendo entre 14,5 anos e 16 anos ${ }^{5,6}$.

No Brasil, a ocorrência da gravidez na adolescência vem apresentando índices preocupantes, tornando-se um desafio para os profissionais da saúde 7 . Dados da Fundação Sistema Estadual de Análise de Dados (Seade) ${ }^{8}$ apontam que no ano de 2002 a ocorrência de partos realizados na adolescência foi de $23,6 \%$ no estado de São Paulo, sendo que especificamente no município de Bauru a taxa correspondeu a 24,9\%.

Entre as complicações da gestação na adolescência, encontra-se 0 abortamento ${ }^{9}$. Essa intercorrência obstétrica destaca-se como um evento que pode ter não só consequências físicas mas também psicológicas ${ }^{10,11}$.

Estima-seque na América Latina eno Caribe ocorram anualmente 18 milhões de gestações, sendo que dessas $52 \%$ não foram planejadas e $23 \%$ terminam em abortamento ${ }^{12}$. No Brasil, calcula-se que $31 \%$ das gestações reconhecidas terminam em abortamento ${ }^{13}$. Porém, alguns estudos ressaltam que a perda fetal espontânea apresenta uma porcentagem mais elevada, em torno de $70 \%$ de todas as gestações, sendo quea utilização de exames especializados evidencia maior número de perdas gestacionais ocorrendo antes do reconhecimento clínico da gravidez ${ }^{14,15}$.

Os números de curetagem pós-abortos realizados pelo Sistema Ú nico de Saúde (SUS) no ano de2002 nafaixa etária da adolescência apontaram uma taxa de $20 \%$ tanto para o estado de São Paulo como para o município de Bauru ${ }^{8}$. Um estudo epidemiológico realizado entre os anos de 2000 e 2003 em um hospital maternidade na cidade de Bauru constatou ocorrência si- milar, ou seja, dos 2.286 abortamentos 459 $(20,08 \%)$ foram em adolescentes ${ }^{16}$.

As consequências de uma gestação prematura e a ocorrência do abortamento podem interferir de forma negativa no cotidiano, trazendo à tona problemas nas esferas biopsicossociais? N esse contexto, o desafio é propiciar ao adolescente acesso a serviços de saúde que lhes ofereça assistência integral, antes mesmo do seu primeiro intercurso sexual, garantindo-Ihe sobretudo privacidade e confiabilidade ${ }^{17}$.

Considerando a necessidade de um atendimento adequado para esse grupo etário, acredita-sequecompreender a experiência interacional acerca dos fenômenos do abortamento a partir dos próprios indivíduos que estão vivenciando a experiência contribuirá, de forma significativa, para a compreensão do processo, minimizando as consequências cuja dimensão estendem-seaos aspectos biopsicossociais dos adolescentes, da família e da sociedade em que se inserem.

\section{Trajetória metodológica}

Estudos realizados por meio da abordagem qualitativa apontam que menor enfoque é dado à generalização, buscando o aprofundamento e a abrangência do grupo estudado ${ }^{18}$. N esse contexto, opto-se por tal metodologia medianteo desejo de descrever ecompreender os fenômenos que compõem a experiência de adolescentes que vivenciaram a perda fetal.

0 presente estudo teve como referencial teórico o interacionismo simbólico e como referencial metodológico a grounded theory.

O interacionismo simbólico possibilita a análise do indivíduo como um ser ativo. Como tal, age no meio baseando-se nos conceitos formulados a partir de vivências próprias, considerando, contudo, possíveis influências da interação com outros e do momento presente; norteado por tais conceitos, o indivíduo direciona suas açõe ${ }^{19}$.

Osconceitos do interacionismo simbólico são: símbolo, self, mente, assumir o papel do outro, ação humana e interação social ${ }^{19}$. Símbolos são os conceitos centrais - sem eles não se podeinteragir com os outros; self é descrito como um objeto social com o qual o indivíduo interage e queestá relacionado com os conceitos sociais que se apresentam no decorrer da vida; mente é a interação simbólica do organismo humano com seu self, ou seja, éa ação que se expressa por meio dos símbolos; assumir o papel do outro significa 
compreender as palavras e ações de outras pessoas; ação humana ocorre a partir da interação com o self e com os outros, ocorrendo reações que se manifestam por meio das interações sociais que emergem do relacionamento dos atos individuais ou de grupos ${ }^{19}$.

A grounded theory baseia-se na descoberta e no desenvolvimento de uma teoria partindo-se das experiências obtidas sistemática e comparativamente. A teoria é gerada por um processo de indução, no qual categorias analíticas emergem dos dados e são elaboradas conforme o trabaIho avança ${ }^{20}$. Esse é um processo descrito como amostragem teórica, uma vez que o número dos sujeitos ou situações que devem integrar o estudo é originado pelo que se determina de saturação teórica, ou seja, quando os dados coletados começam a ser repetidos e novas informações não mais identificadas ${ }^{21}$.

A coleta dos dados ocorreu no ano de 2004, sendo que o critério de inclusão baseou-se no diagnóstico de abortamento independentemente do tipo: espontâneo ou voluntário; forma clínica: completo, incompleto ou retido; e na faixa etária que compreendea adolescência, atéatingir a saturação teórica, que neste estudo se deu com a décima entrevista. Considerou-se essa amostra significativa porque os discursos das adolescentes que dela participaram representaram a construção social do fenômeno do processo de abortamento entre elas e, por extensão, no grupo social a que pertencem, o que foi confirmado por meio de um processo de validação realizado com outras dez adolescentes acometidas pela perda fetal.

O campo de investigação da pesquisa foi 0 Hospital M aternidade Santa Izabel, localizado na cidade de Bauru (São Paulo, Brasil). A escolha dessehospital para desenvolver o estudo deu-sepor se tratar de um centro direcionado ao atendimento da mulher, acolher usuárias do Sistema Único de Saúde, ser referência para vários municípios daregião e hospital de treinamento acadêmico.

Para atingir os objetivos do estudo, os dados foram coletados por meio de entrevista não estruturada, realizada com adolescentes internadas, decorrentes do processo de abortamento, tendo como questão norteadora: como está sendo a experiência de vivenciar 0 abortamento?

As entrevistas foram gravadas e, posteriormente, transcritas integralmente, o que resultou em um material que foi analisado sistemática e comparativamente, sendo seguido pelo início do processo de recorte e codificação. Tais códigos subsidiaram o agrupamento dos dados, sepa- rando-os por semelhança de ideias ou expressões. Após o estudo de cadaum dos códigosidentificados, estes foram agrupados segundo significado, gerando os fenômenos, as categorias e subcategorias que permearam as experiências das adolescentes ao vivenciarem 0 abortamento.

\section{Caracterização do grupo estudado}

0 grupo estudado foi composto por dez adolescentes entre 16 e 19 anos, sendo que dessas somente uma era casada, seis mantinham relação estável com os respectivos parceiros e três moravam com seus familiares. Ressal tamos que a idadegestacional foi verificada na data da internação por meio de ultrassonografia, ocorrendo variação entre a 6 a e a 22a semana de gestação, todas com diagnóstico de abortamento incompleto.

\section{Apresentação da experiência}

Da análise das entrevistas emergiram três fenômenos que representaram o processo vivenciado, sendo caracterizados por: descobrindo-se grávida; vivenciando o abortamento; e reelaborando seu plano de vida.

A descoberta da gravidez, na maioria das vezes, confirmou-se concomitante ao diagnóstico do abortamento.

As experiências mostraram queas adolescentes reconhecem o amadurecimento biológico que as expõe à gravidez, seja ela desejada ou não, e suas consequências, as quais poderão se refletir em várias esferas de sua vida. No grupo estudado, a gestação foi relatada como um evento não planejado.

As experiências revelaram tanto a falta deprevenção contra a gravidez como também o uso incorreto dos métodos contraceptivos, conforme relato das adolescentes:

Eu não sabia que estava grávida, desconfiava porque não uso nada para não engravidar.

Cortei a cartela no meio. Quando parei de tomar, demoraram dez dias; achei que era normal. Depois de vinte dias, resolvi fazer um teste, mas só acreditei quando fiz ultrassom.

$\mathrm{Na}$ iminência da gravidez, as adolescentes negaram os fatos, comparando-os às possibilidades de tal processo não se concretizar:

Eu não queria engravidar, não adorei saber.

Quando a gestação foi constatada, surgiu a necessidade de a adolescente compartilhar com as pessoas de seu convívio a confirmação. Tal momento veio acompanhado de receio e medo das possíveis reações. Os relatos, na maioria das vezes, 
refletiram o desapontamento pelo acontecimento não esperado e as possíveis consequências.

Eu moro com minha irmã. Quando contei para ela, ela disse que estava decepcionada, ficou dias sem conversar comigo. Ela disse que eu tinha traído sua confiança, que tinha me orientado sobre a possibilidade de engravidar e sentia uma faca no peito.

Verificou-se, nas experiências, queo conhecimento da fisiologia da reprodução era constituído de informações incompletas, não só pelas adolescentes, mas também pelos familiares mais próximos, os quais não reconheciam as mudanças fisiológicas relacionadas à maternidade.

Nesse contexto, a adolescente, mesmo tendo consciência da possi bilidade de ter engravidado, não percebia ou não desejava reconhecer as modificações, demonstrando a falta de percepção de um corpo consciente desi.

Eu não acreditei que tava grávida. M inha menstruação estava normal, não tinha enjoo, meu peito não cresceu, minha barriga não cresceu nada... Eu tava normal. A gora, cinco meses!

Pelo relato das adolescentes, identificou-se também que os familiares não perceberam as mudanças decorrentes da gravidez, pelo processo de encontrar-se em fase inicial e/ou também pelo fato de que co-habitar não significa partiIhar os acontecimentos e experiências, as quais, muitas vezes, são vivenciadas de forma solitária.

M inha mãenem imaginava que eu tivesse grávida.

As adolescentes, no decorrer do processo, depararam-se com sinais e sintomas da gravidez ou de intercorrências de tal processo, denunciando a necessidade de buscar atendimento seja na Rede Básica de Saúde ou em ambientes de emergência, sem, contudo, terem a certeza do processo gestacional ou mesmo imaginarem tal possibilidade.

Eu fui ao posto, e o médico pediu exame de gravidez, mas nem cheguei a começar o pré natal.

Começou a descer um negócio bem escuro... Aí, fui para o pronto-socorro.

Eu tava com muita dor, mas já descia há dez dias. Eu achei que não estava normal e procurei 0 pronto-socorro.

O momento da confirmação da gravidez foi caracterizado por um conjunto de sentimentos, principalmente 0 impacto da situação, o que reforça o fato de que apesar de as adolescentes estarem expostas aos riscos da gravidez, não se apresentavam preparadas para enfrentá-la.

0 resultado do testefoi um choque... $\mathrm{N}$ a verdade, foi um desespero.
Os relatos apontaram a rejeição à gravidez, a qual se intensificou a partir da confirmação e, em alguns casos, manteve-se presente mesmo após 0 abortamento, caracterizando 0 acontecimento como algo capaz de solucionar um problema que estava sendo vivenciado.

Agora, sinto um pouco aliviada.

Quando a gravidez evolui, espontaneamente ou não, para perda fetal, as consequências atingem as esferas biopsicossociais, emergindo o segundo fenômeno da experiência: vivenciando 0 abortamento. Esse momento frequentemente foi relatado como difícil etraumático, permeado por vários sentimentos, tais como: medo, culpa, tristeza ealívio.

O diagnóstico do abortamento, informado pela equipe de saúde, médico ou um componente da equipe de enfermagem, algumas vezes foi percebido como amedrontador, não permitindo às adolescentes outra opção, a não ser aceitar sem questionamento.

A enfermeira falou que eu não tinha água no útero; que o neném não ia sobreviver; que, se eu fosse embora, era perigoso ter tétano, uma infecção forte ou ter que arrancar o útero e que podia nunca mais ter filhos.

Com a confirmação do abortamento, a gestação passou a ser alvo de reflexões, surgindo 0 arrependimento por elas não terem tomado determinadas condutas, as quais, acreditavam, poderiam modificar os acontecimentos, denotando a tomada de consciência de uma vida sexual ativa.

Enfrentar as situações decorrentes da perda fetal gerou, além de medo dos procedimentos, sentimentos detristeza, arrependimento, solidão, desamparo e a necessidade de compartilhar o momento com pessoas próximas, além do relato do amor pela "criança”" ea experiênciatraduzida simbolicamente pelo colo vazio.

Aceitar a gravidez já foi difícil; agora, que eu abortei, é muito mais triste.

Se eu tivesse procurado atendimento no meu primeiro sangramento...

Foi uma coisa difícil, eu já tinha pegado amor no nenê.

Foi uma experiência muito difícil eassustadora.

Eu nunca tinha passado por isso. A hora que eu subi para o centro cirúrgico, tive medo daquela injeção na coluna. Nossa Senhora!

As experiências mostraram que as adolescentes tinham necessidade de receber informações para esclarecimento dos motivos efuturas consequências detal intercorrência. Além disso, o apoio, tanto da equipe de saúde quanto das pessoas de 
seu convívio, foi referido como algo necessário, sendo apontado que a presença e o diálogo em uma situação difícil de ser enfrentada foram importantes para a retomada do plano de vida.

Chorei e conversei com as estagiárias que tinha aqui no dia.

Conversar com você ajudou bastante, porque eu não converso disso com ninguém.

0 terceiro fenômeno identificado, reelaborando o plano de vida, retrata a reflexão da adolescente quanto à sua volta ao cotidiano, restabelecendo as relações familiares. Além disso, el as expressaram a necessidade de mudanças de comportamento, objetivando a prevenção de um novo processo gravidez-abortamento; a próxima gravidez deveria ocorrer em condições mais favoráveis, tais como: financeira, de saúde, moradia, de proteção, apoio afetivo e emocional.

Depois que tudo passou, não vejo a hora de ir para casa.

Quero procurar um tratamento para não acontecer denovo, fazer um tratamento para dar certo.

Não pretendo ter outro logo. D epois deum tempo, para meu marido arrumar serviço fixo, quando a gente estiver em nossa casa. N ão quero engravidar agora.

Os fenômenos e seus respectivos componentes foram reunidos e analisados teoricamente e interpretados à luz do interacionismo simbólico. 0 alinhamento detodo o processo permitiu identificar a categoria central que representa o componente-chave da experiência e que possibilitou denominá-la como: "Abortamento na adolescência: da vida à experiência do colo vazio".

\section{Discussão}

Buscar a compreensão do processo do abortamento permitiu constatar tal experiência não como um acontecimento único etransitório, mas como um evento que possui histórico prévio, o qual envolve aspectos biopsicossociais e que não termina após a alta hospitalar, ou seja, um acontecimento relacionado eresultante de uma história de vida passada, presente e futura.

As experiências revelaram que a maioria das adolescentes e as pessoas do seu convívio não se deram conta da ocorrência da gravidez. 0 desconhecimento do funcionamento corporal éum dos fatores que implicam descuido com a prevenção da maternidade/paternidade indesejada ou não planejada ${ }^{23}$.

A prática da sexualidadena adolescência vem reforçando o comportamento sobre a tradição do uso da contracepção como principal atribuição feminina. A paixão pelo namorado transforma-0, através do pensamento mágico, em alguém que a protegerá dos perigos da gravidez $\mathrm{e}$ de doenças sexualmente transmissíveis; assim, a adolescentesente-se sem coragem para seposicionar, em face do parceiro, sobre a necessidade da utilização da anticoncepção ${ }^{24}$.

0 uso inadequado e a falta de informação mais consistente sobre os métodos contraceptivos destacam-se como causas da gravidez na adolescência ${ }^{25,26}$. Embora várias pesquisas apontem que a gravidez na adolescência emerge de um desejo legitímo $0^{27,28}$, neste estudo verificou-se que a constatação da gravidez - a qual foi, na mai oria das vezes, negada - trouxeà tona a conscientização da possibilidade reprodutiva e com ela a emergência de diferentes sentimentos. Estudos afirmam que, passado o primeiro momento de choque, surge uma diversidade de sentimentos, como medo, isolamento, culpa, rejeição, negação, felicidade, conforto e aceitação ${ }^{7}$.

$\mathrm{N}$ as experiências analisadas, não confirmar a gravidez representou a falta de percepção do seu corpo, resultando principalmentena falha em não buscar assistência, retardando o diagnóstico da gravidez, assim como intervenções que poderiam prevenir o abortamento.

A "perda do produto da concepção" não se traduz apenas pela "morte de um bebê"; suas consequências são mais amplas, gerando transtornos que se revelariam em vários aspectos por toda a vida de quem vivenciou tal processo ${ }^{29}$. As adolescentes entrevistadas referiram quea perda fetal gerou sentimentos de tristeza, medo e desamparo.

Por meio de um estudo qualitativo, foi analisado o significado da perda fetal em mulheres que vivenciaram a experiência e constataram que tal evento originou uma ruptura-crise na vida dessas mulheres, implicando a necessidade de reconstrução de sua identidade ${ }^{26}$. A companhar as adolescentes em processo de abortamento permitiu a constatação da necessidade de estratégias que vão além do cuidado imediato inerente a tal intercorrência. Fazem-senecessáriasintervenções em todos os aspectos biopsicossociais, não cabendo aos profissionais a atribuição de juízo de valor, mas sim a compreensão de que a adolescente, por encontrar-se em período de transição entrea infância e a fase adulta, ao enfrentar 0 abortamento sentequeo aflorar de uma nova vidatransformou-se na experiência do colo vazio.

Os referenciais metodológicos e teóricos permitiram compreender que a adolescente consegue definir a situação quando vivencia 0 aborta- 
mento, momento da experiência em queelainterage consigo mesma e com outros atores (marido, companheiro, familiares, equipeetc.) no redirecionamento de sua vida, amparada pelos conhecimentos advindos de sua própria experiência.

\section{Conclusão}

A análise dos relatos feitos pelas adolescentes permitiu visualizar o processo do abortamento, descrito desde a descoberta da gravidez até a ne cessidade de retornar ao cotidiano. 0 processo foi permeado por sentimentos de dúvida, ansie dade, medo, negação e desamparo, intensificados pela falta de conhecimentos prévios, de orientações e de apoio, tanto dos familiares como da equipe de saúde, da qual esperavam maiores esclarecimentos, o que possivel mentefacilitaria a compreensão do evento e as condutas futuras.

0 estudo das experiências das adolescentes, no decorrer de todo o processo do abortamento, evidenciou que tais vivências não devem ser analisadas como um evento isolado, mas sim dentro de um contexto amplo e de imprecisas delimitações, constatando-se que poderiam estar relacionadas à falta de habilidadeevidenciada entre profissionais da saúde, educação, pais e fiIhos em lidar com a sexualidade emergente nessa fase da vida.

Para as adolescentes, enfrentar 0 abortamento traduziu-se na necessidade de amadurecimento e mudança de comportamento; voltar ao cotidiano gerou expectativa e esperança de uma nova vida apoiada pelos familiares. Informações nem sempre são suficientes, fazendo-se necessárias a promoção da educação e a conscientização do exercício de uma sexualidade saudável, as quais são de responsabilidade do indivíduo, da família e dos profissionais da área da saúde e da educação. Outro aspecto resultante dessa pesquisa está atrelado à formação acadêmica, que deveria estimular o comprometimento do estudante, futuro profissional, no desenvolvimento de habilidades relacionadas à abordagem do processo saúdedoença, enfocando entre outros assuntos aqueles relacionados à visão integral do indivíduo no tocante à sexual idade e à saúde reprodutiva.

N esse contexto, ressalta-se a necessidade de maior envolvimento de profissionais das áreas da saúde e educação, além dos familiares, com a final idade de promover a saúde sexual e oferecer assistência imediata às mulheres com diagnóstico deabortamento, principalmenteno grupo das adolescentes, no qual a prevenção da gravidez poderia evitar a ocorrência do abortamento e, consequentemente, melhor qualidade evalorização da vida, produzindo impacto positivo sobre a saúde individual e coletiva.

Analisar 0 abortamento a partir do olhar e da experiência da própria adolescente permitiu o entendimento do processo num contexto biopsicossocial, chamando a atenção para a necessidade de mudanças por parte dos profissionais direta eindiretamente envolvidos, dos quais se espera atuação norteada por um paradigma humanístico eético, livre de preconceitos e juízo de valores.

Ressalta-se, ainda, que este estudo é um re corte da real idade do universo da faixa etária pesquisada, característica do referencial teórico norteador, devendo ser considerado uma construção que sugere novos caminhos a serem pesquisados. 


\section{Colaboradores}

LM Vieira, TBL Goldberg, SO Saes e AAB Dória participaram, igualmente, de todas as etapas de elaboração do artigo.

\section{Referências}

1. World Health Organization (WHO). El embarazo y el aborto en la adolescencia. Ginebra: WHO; 1975. (Informe Técnico, n.583).

2. Goldberg TBL, Jaehn SM, K fouri JRN, Simões ACP, Curi PR. Avaliação do desenvolvimento afetivo-social do adolescente na faixa etária dos 15 aos 18 anos: estudo com adolescentes do município de Botucatu, São Paulo: características sociais e interação familiar. Jornal de Pediatria 1987; 63(4):213-217.

3. Carneiro H, Ladessa LELL, Rodrigues Júnior $O M$, Vaccari VL. Preocupações sexuais de mulheres adolescentes no Brasil. Pediatria Moderna 1997; 33(8):645-653.

4. Brito PL, Almeida ECS. Adolescência: uma visão clínica. Pediatria Atual 1997; 10(5):74-81.

5. Santos Júnior JD. Fatores etiológicos relacionados à gravidez na adolescência: vulnerabilidade à maternidade. In: Schor N, M ota M SFT, Branco VC, organizadores. Cadernos Juventude, Saúde e Desenvolvimento. Brasília: Ministério da Saúde; 1999. p. 223-229.

6. Belo MAV, Silva JLP. Conhecimento, atitude e prática sobre métodos anticoncepcionais entre adolescentes gestantes. Rev Saude Publica 2004; 38(4):479-487.

7. Araújo IMA, Fernandes AFC, Silva RM. Adolescentes grávidas: como vivem estas mulheres? Pediatria Atual 2004; 17(1):35-38.

8. Fundação Sistema Estadual de Análise de Dados (Seade). Conselho de Condição Feminina EstadualSP [on line] 2005. [acessado 2005 out 17]. Disponível em: http://www.seade.gov.br

9. Lima CTB, Feliciano KVO, Carvalho MFS, Souza ADP, M enabó JBC, Ramos LS, Cassundé LF, Kovacs $\mathrm{MH}$. Percepções e práticas de adolescentes grávidas e de familiares em relação à gestação. $\mathrm{Re}$ vista Brasileira de Saúde M aterno Infantil 2004; 4(1):71-83.

10. Costa RG, Hardy E, Osis MJD, Faundes A. A decisão de abortar: processo e sentimentos envolvidos. Cad Saude Publica 1995; 11(1):97-105.

11. Quiala MB, Ojeda SO, Durruti RD, Infante MM . Respuesta del estado psicológico en adolescentes con interrupción del embarazo. Revista Cubana Enfermagem 1999; 15(3):179-183.

12. The Alan Guttmacher Institute. Sharing responsibility: women, society and abortion worldwide. New York: AGI; 1999.

13. Brasil. M inistério da Saúde. Secretaria de Atenção à Saúde. Departamento de Ações Programáticas Estratégicas. Área Técnica de Saúde da Mulher. Atenção humanizada ao abortamento. Brasília: Ministério da Saúde; 2005.

14. Roberts CJ, Lowe DB. Where have all the conceptions gone? The Lancet 1975; 305(7905): 498-499.

15. Boklage CE. Survival probability of human conceptions from fertilization to term. Int J Fertil 1990; 35(2):75-94.

16. Vieira LM. Abortamento na adolescência: da vida à experiência do colo vazio [tese de doutorado]. Botucatu: Departamento de Pediatria da U niversidade Estadual Paulista Júlio de M esquita Filho; 2005. 
17. Brasil. M inistério da Saúde. Secretaria de Política de Saúde. Área Técnica de Saúde da Mulher. Planejamento familiar: manual para o gestor. Brasília: Ministério da Saúde; 2002.

18. M inayo M CS. 0 desafio do conhecimento: pesquisa qualitativa em saúde. São Paulo: Hucitec; 2000.

19. Charon JM. Symbolic interactionism: an introduction, an interpretation, an integration. New York: Prentice Hall; 1989.

20. Glaser BG, Strauss AL. The discovery of grounded theory: strategies for qualitative research. New York: Aldine; 1967.

21. Strauss A, Corbin J. Basics of qualitative research: grounded theory - procedures and techniques. $\mathrm{New}$ bury Park: Sage Publication; 1990.

22. Brasil. Conselho Nacional de Saúde. Resolução n 196, de 10 de outubro de 1996. Diretrizes e normas regulamentadoras de pesquisa envolvendo seres humanos. Brasília: M inistério da Saúde; 1996.

23. Mandu ENT. Adolescência: saúde, sexualidade e reprodução. In: Associação Brasileira de Enfermagem, organizador. Adolescer, compreender, atuar, acoIher. Brasília: M inistério da Saúde; 2001. p. 61-74.

24. Oliveira M W. Gravidez na adolescência: dimensões do problema. Cadernos Cedes 1998; 19(45): 48-70.

25. Amazarray MR, Machado PS, Oliveira VZ, Gomes WB. A experiência de assumir a gestação na adolescência: um estudo fenomenológico. Psicologia Reflexão e Crítica 1998; 11(3):431-440.

26. Santos ALD, Rosenburg CP, Buralli KO. Histórias de perdas fetais contadas por mulheres: estudo de análise qualitativa. Rev Saude Publica 2004; 38(2):268276.

27. Pires DR. Estudo do perfil da gestante adolescente quanto aos aspectos sociais, psicológicos e preventivos em M andiritiba, PR [tese]. Curitiba: Departamento de Ciências da Saúde, Universidade Federal do Paraná; 2004.

28. Catharino TR, Giffin K. Gravidez e adolescência: investigação de um problema moderno. In: Anais do XII Encontro Nacional da Abep; 2002; Rio de Janeiro. p. 1.

29. Quayle J. Aspectos emocionais em perdas gestacionais. Revista Psicologia Hospitalar 1992; 1(2):52-55.

Artigo apresentado em 16/08/2007

Aprovado em 16/07/2008

Versão final apresentada em 10/09/2008 